\title{
Computational Virtual Screening of Sulfonylurea chalcones as New Class of 5-Lipoxygenase Inhibitors by Molecular Docking Studies
}

\author{
Bharat Kumar Bugata \\ Research Scholar \\ Department of Bioinformatics \\ Gitam University, INDIA
}

\author{
SVGK Kaladhar Dowluru \\ Asst. Professor \\ Department of Bioinformatics \\ Gitam University, INDIA
}

\author{
Vasudeva Rao Avupati \\ CSIR-SRF, New Delhi \\ Pharmaceutical Chemistry Labs \\ Andhra University, INDIA
}

\begin{abstract}
Molecular docking study was performed on a series of 25 sulfonylureachalcones VS1-VS25 as potential 5-lipoxygenase (5-LO) inhibitors. The docking technique was applied to dock a set of representative compounds within the active site region of 3V99 (5-LO) using Molegro Virtual Docker v 4.0. For these compounds, the binding free energy $(\mathrm{kcal} / \mathrm{mol})$ was determined. The docking simulation clearly predicted the binding mode that is nearly similar to the crystallographic binding mode with $1.17 \mathrm{~A}^{\circ}$ RMSD. Based on the validations and hydrogen bond interactions made by $\mathrm{R}$ substituents were considered for evaluation. The results avail to understand the type of interactions that occur between designed ligands with $3 \mathrm{~V} 99$ binding site region and explain the importance of $\mathrm{R}$ substitution on sulfonylureachalcone basic nucleus.
\end{abstract}

\section{Keywords}

Molecular Docking, Sulfonylureachalcones, 5-lipoxygenase (5-LO), Molegro Virtual Docker (MVD).

\section{INTRODUCTION}

Drug discovery and development is an interdisciplinary, expensive and time consuming process. Scientific technology advancements during the past two decades have changed the approach of the pharmaceutical research to generate novel bioactive molecules. Advances in computational techniques and in parallel hardware support have enabled in silico methods, and in particular structure-based drug design method, to speed up new target selection through the identification of hits to the optimization of lead compounds in the drug discovery process. Genomics, proteomics, bioinformatics and chemoinformatics have gained immense popularity and have become an integral part of the industrial and academic research, directing drug design and discovery. Virtual screening emerged as an important tool in our quest to access novel drug like compounds [1-3].

Rational in silico drug design can be done in two ways: ligand-based or structure-based. With the availability of the 3D structure of a biological target, it is feasible to use a structure-based approach to evaluate and predict the binding mode of a ligand within the active site of the receptor with docking methods [4-8]. Now it is a popular technique used for increasing the speed of drug designing process. This was made possible by the availability of many protein structures which helped in developing tools to understand the structure function relationships, automated docking and virtual screening. Furthermore, when no 3D structural information about target proteins with their receptor site is available ligand-based design is applied [9-12]. The ligand-based approach starts with a group of ligands binding to the same receptor with the same mechanism. Today four different strategies based on the prior knowledge of the targets 3D structure and the ligands binding to it are predominant [13].

5-Lipoxygenase (5-LO) [14] plays an essential role in the biosynthesis of leukotrienes (LTs) that exert a large number of different biological activities mediated by specific Gprotein coupled receptors. $\mathrm{LTB}_{4}$ is a typical proinflammatory mediator that recruits and activates leukocytes, whereas cysteinyl-leukotrienes $\quad \mathrm{C}_{4}, \quad \mathrm{D}_{4}$ and $\mathrm{E}_{4}$ cause vascular permeability and smooth muscle contraction. In view of these properties, development of drugs with 5-LO inhibitory activity has been hypothesized to possess therapeutic potential for treatment of asthma, allergic disorders and other inflammatory diseases. Thus there is a need for rapid and efficient computational methods capable of differentiating compounds with acceptable biopharmaceutical properties, e.g. solubility, lipophilicity, ionization constant etc at an early stage in the drug discovery process. In the present study, Ligand Protein Inverse Docking (LPID) stratagies were employed on set of 25 sulfonylureachalcones. Through In Silico docking procedures different modes of interactions exhibited by these newly designed ligands will be recognized and further examined for their predicted binding energies.

\section{MATERIALS AND METHODS}

\subsection{Software Methodology}

In the present molecular docking study, software Molegro Virtual Docker (MVD) v 5.0 (www.molegro.com) along with Graphical User Interface (GUI), MVD tools was utilized to generate grid, calculate dock score and evaluate conformers. Molecular docking was performed using MolDock docking engine of software. The scoring function used by MolDock is derived from the Piecewise Linear Potential (PLP) scoring functions. The active binding site region was defined as a spherical region which encompasses all protein within 15.0 $\mathrm{A}^{\mathrm{o}}$ of bound crystallographic ligand atom with selected coordinates of $\mathrm{X}, \mathrm{Y}$ and $\mathrm{Z}$ axes, respectively. Default settings were used for all the calculations. Docking was performed using a grid resolution of $0.30 \mathrm{~A}^{\mathrm{o}}$ and for each of the 10 independent runs; a maximum number of 1500 iterations were executed on a single population of 50 individuals. The active binding site was considered as a rigid molecule, whereas the ligands were treated as being flexible, i.e. all non-ring torsions were allowed [15]. 


\subsection{Molecular Modeling}

A set of 25 new sulfonylureachalcones VS1-VS25 listed in Table 1, were designed and modeled based on the compounds synthesized and reported earlier by one of the authors Vasudeva Rao Avupati et al [16]. In the present study, meta isomers have been constructed and subjected for molecular docking experiments. However, certain chemical rules are utilized to prevent unreasonable structures during molecular design. For instance, structures that include heteroatoms bonded to each other (e.g. O-O, N-N and $\mathrm{N}-\mathrm{O}$ etc) and eliminating too many heteroatoms bonded to the same carbon atom. Also, certain fragments attached to an aromatic ring possess toxicity.

\subsection{Ligand Preparation}

The structures of sulfonylureachalcones VS1-VS25 were drawn using Chemdraw ultra v 10.0 (Cambridge software), copied to Chem3D ultra v 10.0 to create a 3D model and, finally subjected to energy minimization using molecular mechanics $\left(\mathrm{MM}_{2}\right)$. The minimization was executed until the root mean square gradient value reached a value smaller than $0.001 \mathrm{kcal} / \mathrm{mol}$. Such energy minimized structures are considered for docking and corresponding pdb files were prepared using Chem3D ultra v 10.0 integral option (save as /Protein Data Bank (pdb)) (Table 1) [17].

\subsection{Protein Selection}

The selection of protein for docking studies is based upon several factors i.e. structure should be determined by X-ray diffraction, and resolution should be between $2.0-2.5 \mathrm{~A}^{\circ}$, it should contain a co-crystallized ligand; the selected protein should not have any protein breaks in their 3D structure. However, we considered ramachandran plot statistics as the important filter for protein selection that none of the residues present in disallowed regions [18].

\subsection{Protein Preparation}

All 5-LO X-ray crystal structures were obtained from the Brookhaven Protein Data Bank (http://www.rcsb.org/pdb). Subsequent to screening for the above specific standards the resultant protein target (PDB Code: 3V99) was selected and prepared for molecular docking simulation in such a way that all heteroatoms (i.e., nonreceptor atoms such as water, ions, etc.) were removed and Kollmann charges were assigned [19].

\subsection{Software Method Validation}

Software method validation was performed in MVD using Protein Data Bank (PDB) protein 3V99. The x-ray crystal structure of 3V99 complex with Arachidonic acid was recovered from PDB. The bio active co-crystallized bound ligand $\quad(5 Z, 8 Z, 11 Z, 14 Z)$-icosa-5,8,11,14-tetraenoic acid (Arachidonic acid, $\mathrm{C}_{20} \mathrm{H}_{32} \mathrm{O}_{2}$ ) was docked with in the active site region of $3 \mathrm{~V} 99$. The RMSD of all atoms between the two conformations is $1.17 \mathrm{~A}^{\mathrm{o}}$ indicating that the parameters for docking simulation are good in reproducing X-ray crystal structure.

\subsection{Molecular Docking}

In the present investigation, we make use of a docking algorithm called MolDock. MolDock is based on a new hybrid search algorithm, called guided differential evolution. The guided differential evolution algorithm combines the differential evolution optimization technique with a cavity prediction algorithm. We used MVD because it showed higher docking accuracy than other stages of the docking products (MVD: 87\%, Glide: 82\%, Surflex: 75\%, FlexX: $58 \%)$ in the market $[20,21]$.
Table 1. Sulfonylureachalcones VS1-VS25 with their Moldock Scores and corresponding H-bonds interactions against 5-lipoxygenase (PDB Code: 3V99)<smiles>[R]C=CC(=O)c1cccc(NC(=O)NS(=O)(=O)c2ccc(C)cc2)c1</smiles>

\begin{tabular}{|c|c|c|c|}
\hline $\begin{array}{l}\text { Ligand } \\
\text { Code }\end{array}$ & $\begin{array}{l}\text { 'R' Group } \\
\text { Substituent }\end{array}$ & $\begin{array}{l}\text { Moldock } \\
\text { Score } \\
\text { (kcal/mol) }\end{array}$ & $\begin{array}{l}\text { No. of H-Bonds / } \\
\text { H-bond } \\
\text { Interacting } \\
\text { Residues } \\
\end{array}$ \\
\hline VS1 & $\mathrm{C}_{6} \mathrm{H}_{5}$ & -156.987 & $\begin{array}{l}\text { 2/Asn } 554 \text { and } \\
\text { Ala } 606\end{array}$ \\
\hline VS2 & 4- $\mathrm{MeC}_{6} \mathrm{H}_{4}$ & -143.998 & 1/Lys 409 \\
\hline VS3 & $4-\mathrm{NMe}_{2} \mathrm{C}_{6} \mathrm{H}_{4}$ & -189.247 & $\begin{array}{l}\text { 3/Val 671, His } \\
367 \text { and Asn } 554\end{array}$ \\
\hline VS4 & $\begin{array}{l}\text { 2,4-diOMe } \\
\mathrm{C}_{6} \mathrm{H}_{3}\end{array}$ & -156.275 & 1/Gln 557 \\
\hline VS5 & $\begin{array}{l}3,4,5- \\
\text { triOMeC }{ }_{6} \mathrm{H}_{2}\end{array}$ & -172.513 & 1/Asn 554 \\
\hline VS6 & $2-\mathrm{OHC}_{6} \mathrm{H}_{4}$ & -189.825 & $\begin{array}{l}\text { 3/Asn 554, Gln } \\
557 \text { and Tyr } 558\end{array}$ \\
\hline VS7 & $3-\mathrm{OHC}_{6} \mathrm{H}_{4}$ & -193.641 & $\begin{array}{l}\text { 3/Asn 554, Ser } \\
608 \text { and Ala } 606\end{array}$ \\
\hline VS8 & $4-\mathrm{OHC}_{6} \mathrm{H}_{4}$ & -157.347 & 1/Gln 557 \\
\hline VS9 & $\begin{array}{l}\text { 3-OEt, } \\
\text { 4-OHC } 6 \mathrm{H}_{3}\end{array}$ & -154.115 & $\begin{array}{l}\text { 2/Gln } 363 \text { and } \\
\text { Val } 604\end{array}$ \\
\hline VS10 & $\begin{array}{l}\text { 3-OMe, } \\
4-\mathrm{OHC}{ }_{6} \mathrm{H}_{3}\end{array}$ & -152.463 & 1/Tyr 558 \\
\hline VS11 & $2-\mathrm{NO}_{2} \mathrm{C}_{6} \mathrm{H}_{4}$ & -167.298 & 1/Gln 609 \\
\hline VS12 & $3-\mathrm{NO}_{2} \mathrm{C}_{6} \mathrm{H}_{4}$ & -139.753 & - \\
\hline VS13 & $\begin{array}{l}5-\mathrm{OH}, 2-\mathrm{NO}_{2} \\
\mathrm{C}_{6} \mathrm{H}_{3}\end{array}$ & -193.434 & $\begin{array}{l}\text { 3/Asn 554, Ala } \\
606 \text { and GIn } 609\end{array}$ \\
\hline VS14 & $3-\mathrm{FC}_{6} \mathrm{H}_{4}$ & -154.518 & 1/Phe 177 \\
\hline VS15 & $4-\mathrm{FC}_{6} \mathrm{H}_{4}$ & -146.732 & $\begin{array}{l}\text { 2/Asn } 554 \text { and } \\
\text { Phe } 177\end{array}$ \\
\hline VS16 & $2-\mathrm{ClC}_{6} \mathrm{H}_{4}$ & -151.134 & 1/Ala 672 \\
\hline VS17 & 4- $\mathrm{ClC}_{6} \mathrm{H}_{4}$ & -191.051 & $\begin{array}{l}\text { 3/Asn 554, Gln } \\
557 \text { and Gln } 609\end{array}$ \\
\hline VS18 & $2,4-\mathrm{diClC}_{6} \mathrm{H}_{3}$ & -150.269 & - \\
\hline VS19 & $3-\mathrm{BrC}_{6} \mathrm{H}_{4}$ & -151.336 & - \\
\hline VS20 & 4- $\mathrm{BrC}_{6} \mathrm{H}_{4}$ & -149.916 & - \\
\hline VS21 & 4-Allyl- $\mathrm{OC}_{6} \mathrm{H}_{4}$ & -171.914 & - \\
\hline VS22 & Phenylethenyl & -166.069 & $1 /$ His 367 \\
\hline VS23 & Pyridin-3-yl & -143.322 & - \\
\hline VS24 & Pyridin-4-yl & -150.84 & 1/Tyr 558 \\
\hline VS25 & Anthracen-9-yl & -173.39 & $\begin{array}{l}2 / \text { Tyr } 558 \text { and } \\
\text { Asn } 554\end{array}$ \\
\hline $\begin{array}{l}\text { Crystal } \\
\text { Ligand }\end{array}$ & $\begin{array}{l}\text { Arachidonic } \\
\text { acid }\end{array}$ & -94.38 & - \\
\hline
\end{tabular}


Molecular docking technique was employed to dock the designed sulfonylureachalcones VS1-VS25 listed in (Table 1) against 5-LO receptor $3 \mathrm{~V} 99$ using MVD to locate the interaction between various compounds and 5-LO. MVD requires the receptor and ligand coordinates in either Mol2 or PDB format. Non polar hydrogen atoms were removed from the receptor file and their partial charges were added to the corresponding carbon atoms. Molecular docking was performed using MolDock docking engine of Molegro software. The binding site was defined as a spherical region which encompasses all protein atoms within $15.0 \mathrm{~A}^{\mathrm{o}}$ of bound crystallographic ligand atom (dimensions $\mathrm{X}\left(18.42 \mathrm{~A}^{\circ}\right)$, Y ($\left.78.40 \mathrm{~A}^{\circ}\right), \mathrm{Z}\left(-33.21 \mathrm{~A}^{\circ}\right.$ ) axes, respectively). Default settings were used for all the calculations. Docking was performed using a grid resolution of $0.3 \mathrm{~A}^{\mathrm{o}}$ and for each of the 10 independent runs; a maximum number of 1500 iterations were executed on a single population of 50 individuals.

Fig 1: Superimposed binding orientation of docked conformer (yellow) and most stable ligand VS13 (white) within the active binding site region of $3 \mathrm{~V} 99$.

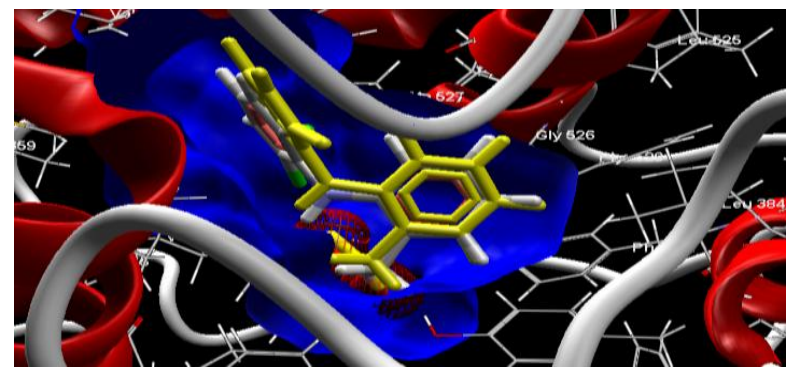

\section{RESULTS AND DISCUSSION}

Ligand-Protein Inverse Docking (LPID) approach has been used as a useful tool in facilitating drug design. In this approach, docking single or multiple small molecules in single or multiple conformations to a receptor site is attempted to find putative ligands. A number of flexible docking algorithms have been introduced. These include multiple-conformer shape matching, genetic algorithm, evolutionary programming, simulated annealing, fragmentbased docking, and other novel algorithms. Testing results have shown that these algorithms are capable of finding ligands and binding conformations at a receptor site close to
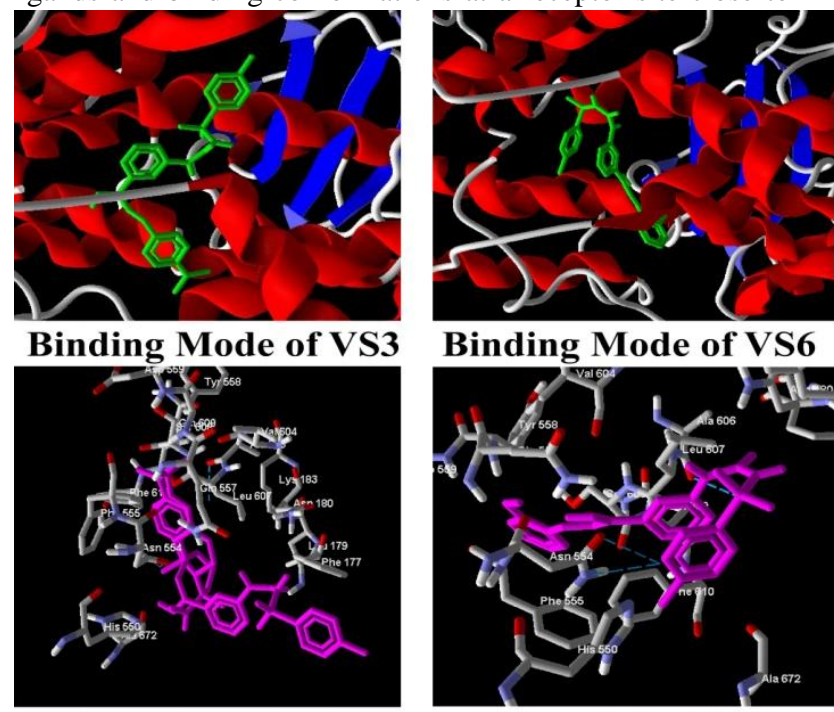

H-bonds by VS3

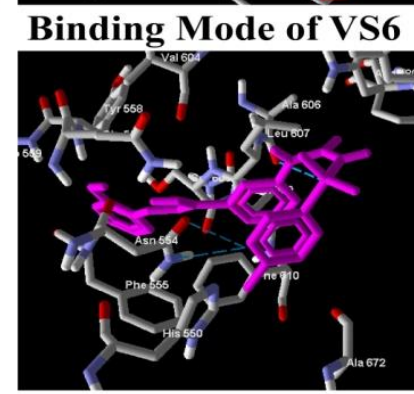

H-bonds by VS6 experimentally determined structures. Because of their capability in identifying potential ligands and binding conformations, these algorithms are expected to be equally applicable to an inverse-docking process for finding multiple putative protein targets to which a small molecule can bind or weakly bind. This may be applied to the identification of unknown and secondary therapeutic targets of drugs, drug leads, natural products and other ligands. LPID approach is now applied to the database of 25 compounds in the present study for finding 'best fit' (hit identification) against 5-LO. The compound with least binding energy against target protein is considered for further study. By this means, it is possible to understand how the compounds interact with the target protein. The results emerging out of this study can be used to identify the binding properties of compounds synthesized in the present study.

The ligand-protein inverse docking simulation technique was performed using MVD program with 25 designed sulfonylureachalcones VS1-VS25 with basic $\alpha, \beta$-unsaturated ketone moiety reported to be having 5-lipoxygenase inhibitory activity. Docking simulations with 3V99 bound ligand Arachidonic acid resulted in a Moldock score of -94.38 $\mathrm{kcal} / \mathrm{mol}$ and a RMSD value of $1.17 \mathrm{~A}^{\mathrm{o}}$ showed no hydrogen bond interactions with in the active binding site region. Docking studies on experimental compounds (Table 1) showed that most of the compounds are involved in hydrogen bonding with residues Asn 554 and Tyr 558 in the binding site region of $3 \mathrm{~V} 99$. Therefore, although other H-bond interactions exist, these hydrogen bonds are relevant for the binding activities of sulfonylureachalcones to be highly selective and potent 5-LO inhibitors. Moreover, from the data given in (Table 1), it appears that the residues Asn 554 represent most significant residue for binding diverse range of compounds. The important residue that participates in H-bond interactions was recognized by our studies on experimental compounds. Therefore, this approach appears to be useful in predicting key interacting ligand binding residue. Hence interaction with Asn 554 which is common interacting residue among all the compounds with stable binding conformations as seen in case of compounds such as VS3, VS6, VS7, VS13 (Fig 1) and VS17 with Moldock Score i.e. least binding energies $-189.247,-189.825,-193.641, \mathbf{- 1 9 3 . 4 3 4}$ and -191.051 $\mathrm{kcal} / \mathrm{mol}$ respectively (Fig 2 )
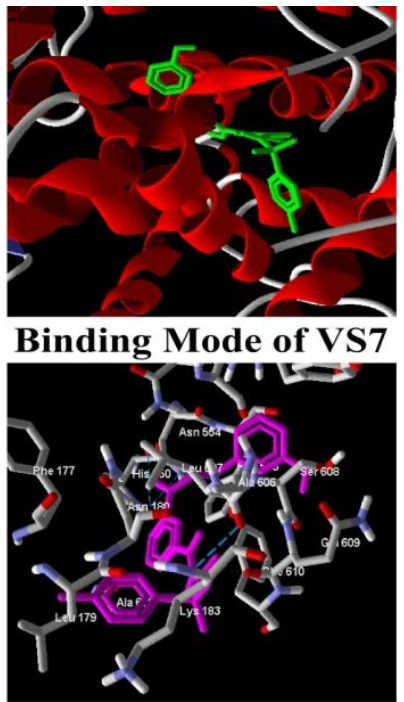

H-bonds by VS7
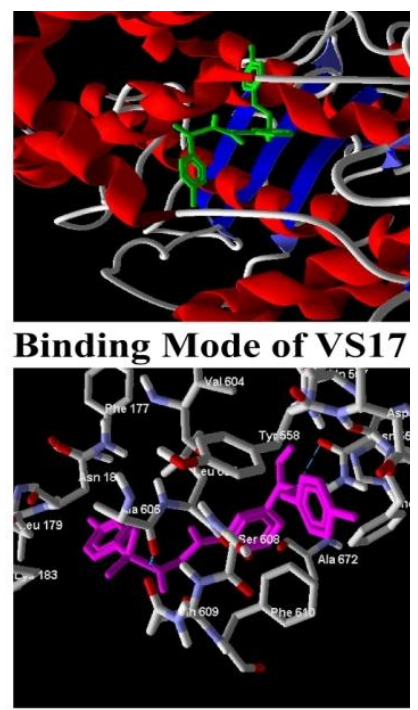

H-bonds by VS17

Fig 2: Shows binding mode and hydrogen bond interactions of most stable ligands (Yellow, Pink) in the binding site region of 3V99. The side chains of the residues are shown in stick model. Red ribbon represents the secondary structure of the protein. 


\section{CONCLUSIONS}

In this study the ligand-protein molecular docking simulation was used to preliminarily investigate and to confirm the potential molecular target for the designed ligands VS1-VS25. The analysis of the best docked ligands against selected target revealed the binding mode of compounds involved in this study and confirm the role as 5-LO inhibitors. Binding energies of the drug-enzyme (receptor) interactions are important to describe how fit the drug binds to the target macromolecule. The residues participated in the hydrogen bond formation within the active binding site region revealed the importance of these residues towards the observed binding energy with respect to the hit identified against 5-LO target protein. The obtained hypothesis could be the remarkable starting point to develop some new leads as potential 5-LO inhibitors with enhance the affinity as well as intrinsic activity. The results of this work indicate efficient computational tools are capable of identify potential ligands such as VS3, VS6, VS7, VS13 and VS17, even though their biological profile has not known. The utilization of computational tools in the drug discovery and development can be used to save time and reduce the bench work of a medicinal chemist.

\section{ACKNOWLEDGMENTS}

One of the authors Mr. Bharat Kumar Bugata is thankful to Dr. Vasudeva Rao Avupati for his constant supervision and support during the course of my research work.

\section{REFERENCES}

[1] Drews, J. (2000) Drug discovery: A historical Perspective. Scinece 287, 1960-1964.

[2] Ohlstein, EH., Ruffolo Jr., R.R., and Ellroff, J.D. (2000) Drug discovery in the next millennium. Annu. Rev. Pharmacol. Toxicol. 40, 177-191.

[3] Royer RJ. Mechanism of action of adverse drug reactions: An overview. 1997; Pharmcoepidemiology and drug safety 6 (Suppl.):S43-S50.

[4] DiMasi JA, Bryant, NR, Lasagna L. (1991). New drug development in the United States from 1963 to 1990. Clin Pharmacol Ther. 50, 471-486.

[5] Chen Y.Z., and Zhi D. G., (2001). Ligand-Protein Inverse Docking and Its Potential Use in Computer Search of Putative Protein Targets of a Small Molecule. Proteins, 43, 217-226

[6] Chen Y.Z., and Ung C. Y. (2002). Computer Automated Prediction of Putative Therapeutic and Toxicity Protein Targets of Bioactive Compounds from Chinese Medicinal Plants, Am. J. Chin. Med., 30, 139-154. (2002)

[7] Chen Y.Z., and Ung C. Y. (2001). Prediction of Potential Toxicity and Side Effect Protein Targets of a Small Molecule by a Ligand-Protein Inverse Docking Approach. J. Mol. Graph. Mod., 20, 199-218.

[8] Cornell, WD, Cieplak P, Bayly CI, Gould IR, Merz KM Jr, Ferguson DM, Spellmeyer DC, Fox T, Caldwell JW, Kollman PA. A second generation force field for the simulation of proteins and nucleic acids. J. Am. Chem. Soc. 1995; 117:5179-5197.
[9] Lorber DM, Shoichet BK. Flexible ligand docking using conformational ensembles. Protein Sci. 7:938-950. 1998.

[10] Schmidt TJ, Meyer AS. Autoregulation of corticosteroid receptors. How, when, where, and why? Receptor. 1994 Winter;4:229-257.

[11] Sandak B, Wolfson HJ, Nussinov R. Flexible docking allowing induced fit in proteins: insights from an open to closed conformational isomers. Proteins 1998;32:159174.

[12] Noreen Y, Serrano G, Perera P, Bohlin L. Flavan-3-ols isolated from some medicinal plants inhibiting COX-1 and COX-2 catalysed prostaglandin biosynthesis. Planta Med. 64:520-524. 1998

[13] Carlson HA, McCammon JA. Accommodating protein flexibility in computational drug design. Mol. Pharmacol. 2000; 57:213-218.

[14] Oliver W and Dieter S (2005) Pharmacological intervention with 5-lipoxygenase: new insights and novel compounds. Expert Opin Therapeutic Patents. 15 (5), 505-519.

[15] Gehlhaar, D. K.; Verkhivker, G.; Rejto, P. A.; Fogel, D. B.; Fogel, L. J.; Freer, S. T. (1995) Docking Conformationally Flexible Small Molecules Into a Protein Binding Site Through Evolutionary Programming. Proceedings of the Fourth Internationa Conference on Evolutionary Programming, No 123-124.

[16] Vasudeva Rao Avupati, Rajendra Prasad Yejella, Annapurna Akula, Girija Sankar Guntuku, Bhagya Raju Doddi, Venkata Rao Vutla, Suvarna Ratna Anagani, Lakshmana Santhi Adimulam, Aruna Kumar Vyricharla (2012) Synthesis, characterization and biological evaluation of some novel 2,4-thiazolidinediones as potential cytotoxic, antimicrobial and antihyperglycemic agents. Bioorganic \& Medicinal Chemistry Letters, 22 $6442-6450$

[17] Berman H M, Westbrook J, Feng Z, Gilliland G, Bhat T N, Weissig H, Shindyalov I N, Bourne P E (2000) The Protein Data Bank. Nucleic Acids Research, 28, 235242.

[18] Wang, J, Kollman, PA, Kuntz, ID. Flexible ligand docking: A multistep strategy approach. Proteins. 1999; 36:1-19.Bowman, M., Debray, S. K., and Peterson, L. L. 1993. Reasoning about naming systems.

[19] Ramachandran, G. N., Sasisekharan, V. (1968) Conformation of polypeptides and proteins. Adv. Protein Chem. 23, 283-438.

[20] Vasudeva Rao Avupati, Purna Nagasree Kurre, Santoshi Rupa Bagadi, Muralikrishna Kumar Muthyala and Rajendra Prasad Yejella (2010) Denovo Based Ligand generation and Docking studies of PPAR $\delta$ Agonists. Correlations between Predicted Biological activity vs. Biopharmaceutical Descriptors. 10, 74-86.

[21] Storn, R., Price, K. Differential Evolution - A Simple and Efficient Adaptive Scheme for Global Optimization over Continuous Spaces. Tech-report, International Computer Science Institute, Berkley, 1995. 